\title{
Inhibición de colonización intestinal por Vibrio cholerae con Lactobacillus acidophilus1 en conejos lactantes
}

\section{Lactobacillus probiotics may prevent Vibrio cholerae colonization in rabbits newborn}

\author{
Alvaro Pazos M, ${ }^{1 *}$ Ph.D, Milena Guerrero ${ }^{1},{ }^{1}$.SC. \\ ${ }^{1}$ Universidad de Nariño, Facultad de Ciencias Exactas y Naturales, Departamento de Biología, Pasto, \\ Colombia. *Correspondencia: alpazmo@udenar.edu.co.
}

Recibido: Octubre de 2012; Aceptado: Mayo de 2013.

\begin{abstract}
RESUMEN
Objetivo. Evaluar la capacidad in vitro e in vivo de Lactobacillus acidophilus1, aislado en este estudio, para prevenir enfermedad diarreica causada por Vibrio cholerae 01 OGAWA, en conejos lactantes. Materiales y métodos. Se aisló Lactobacillus acidophilus1 a partir de heces de niños sanos, se seleccionó por su capacidad amilolítica a partir de un grupo de bacterias ácido lácticas (BAL). El mejor sustrato amiláceo para el crecimiento de la BAL fue estandarizado previamente. Con L. acidophilus1 se realizó un ensayo in vitro e in vivo de inhibición antagónica sobre el enteropatógeno y se evaluó la prevención de la colonización por $V$. cholerae 01 OGAWA en conejos lactantes. Resultados. De acuerdo con el análisis de varianza $L$. acidophilus1 presentó la mejor capacidad amilolítica respecto a las otras BAL aisladas, $\mathrm{p}<0.5$. Se encontró que un inóculo con una densidad celular de $35 \times 10^{6}$ bacterias $/ \mathrm{ml}$ en el fermento láctico es capaz de ejercer el mayor efecto antagónico in vitro sobre $V$. cholerae. Se demostró el efecto probiótico in vivo, ya que los conejos enfrentados con el patógeno y sin recibir probiótico tuvieron una probabilidad de sobrevida menor de 0.25 respecto al grupo de animales retados con el patógeno y simultáneamente alimentados con el probiótico cuya probabilidad de sobrevida fue de 0.95. Conclusiones. L. acidophilus1 se considera un microorganismo probiótico, capaz de sobrevivir a su paso por el tracto gastrointestinal en un modelo animal y prevenir la colonización intestinal por $v$. cholerae 01 OGAWA en conejos lactantes.
\end{abstract}

Palabras clave: Conejos, Lactobacillus acidophilus, probióticos, Vibrio cholerae, (Fuente: DeCS).

\begin{abstract}
ABSCRACT
Objective. To assess the capacity in vitro and in vivo of Lactobacillus acidophilus 1 isolated in this study, capable of preventing diarrheal disease caused by Vibrio cholerae 01 OGAWA in rabbits newborn. Materials and methods. Lactobacillus acidophilus 1 was isolated from faeces of healthy children and was selected from a group of lactic acid bacteria (LAB). The better starchy substrate for the growth of the LAB was previously standardized. Using the L. acidophilus 1 , there was carried out an in vitro and in vivo assay of antagonistic inhibition on the enteropathogen and it was evaluated the prevention of colonization by $V$. cholerae 01 Ogawa in rabbits newborn. Results. L. acidophilus 1 present the better amylolytic capacity, $p<0.5$ in the ANDEVA. It was found that an inoculum with a cell density of
\end{abstract}


$35 \times 10^{6}$ bacteria/ $\mathrm{ml}$ in the lactic ferment is able to exert the greatest antagonistic effect in vitro over $V$. cholerae. The probiotic effect was demonstrated in vivo, since rabbits exposed to the pathogen without having received probiotic had a lower survival probability of 0.25 regarding the group of animals exposed with the pathogen and simultaneously fed with the probiotic whose probability of survival was of 0.95 . Conclusions. L. acidophilus 1 is considered a probiotic microorganism capable of surviving when passing through the gastrointestinal tract in an animal model and preventing intestinal colonization by $V$. cholerae 01 Ogawa in rabbits newborn.

Key words: Lactobacillus acidophilus, probiotics, rabbits, Vibrio cholerae (Source: MeSH).

\section{INTRODUCCIÓN}

A nivel mundial las enfermedades infecciosas continúan siendo el principal problema por resolver en el siglo XXI. Según la OMS, las enfermedades diarreicas son la segunda mayor causa de muerte en niños menores de cinco años. En 2012, fueron reportados por la OMS 245.393 casos de cólera con más del $49 \%$ de los casos ocurridos en América, principalmente en Haití y Republica Dominicana (1). En Colombia, en el periodo Enero-Agosto de 2013 se documentaron 76 muertes por enfermedad diarreica aguda (EDA) en lo corrido del año y 1.878 .989 casos, de los cuales $25.1 \%$ en niños menores de 5 años. En comparación con el año 2012, hasta Agosto de 2013 en Colombia se registró un aumento de $14.4 \%$ de mortalidad por EDA (2).

Las bacterias de los géneros Shigella, Campylobacter y las especies $V$. cholerae, E. coli patogénica y rotavirus, son los principales agentes causantes de muertes por EDA en países emergentes. En Estados Unidos de 21 a 37 millones de casos de EDA se producen por año en una población de 16.5 millones de niños y en tales casos Salmonella, Campylobacter y E. coli 0157 enterohemorrágica y enteroagregativa son las bacterias mas frecuentes de infecciones transmitidas por alimentos (3). La alta incidencia de las infecciones asociadas a estos agentes se debe principalmente a su fácil diseminación, los perfiles de resistencia a los fármacos antimicrobianos y los complejos mecanismos moleculares de patogenicidad (4).

El cólera es la EDA más grave que se conoce y se caracteriza por su rápida diseminación que conlleva a epidemias en periodos cortos de tiempo. Es producida por la bacteria $V$. cholerae que se encuentra en el agua o alimentos contaminados y puede causar la muerte de $50 \%$ de los infectados.

En países como Haití y República Dominicana se reporta una letalidad alta por cólera; con un número de casos de muertes de 8258 y 453 casos acumulados hasta agosto de 2013 respectivamente (2), lo anterior sumado a que el flujo de inmigrantes y visitantes entre estos países y Colombia es considerable, creemos pertinente tener en cuenta el Plan Nacional para el Control del Cólera (PNCC) que se desarrolla en Colombia desde el año 2011, en particular con relación al desarrollo de estrategias de prevención que permitan evitar la aparición de brotes o epidemias. La creación del PNCC se sustenta en epidemias que sobrevinieron con el terremoto de Haití en 2009, con lo cual el número de casos en este país y República Dominicana y por tanto, el riesgo de brotes en Centroamérica y Suramérica se incrementaron considerablemente en los últimos años. Por otro lado, aun cuando se establecen las medidas sanitarias y de prevención, la alta incidencia de EDA se convierte en un serio problema de salud pública a nivel mundial, por lo cual los esfuerzos para conseguir estrategias de manejo y control de estas infecciones son de constante interés científico.

La microbiota gastrointestinal humana (MIH) juega un papel importante en la salud del individuo dado que la composición y la actividad de los microorganismos son responsables de funciones metabólicas colectivas, de barrera e interacciones con el huésped $(5,6)$. Trillones de microorganismos habitan el intestino humano, formando una comunidad ecológica compleja que influencia en su normal funcionamiento $y$ en la susceptibilidad a enfermedades (7). Las BAL autóctonas del tracto gastrointestinal humano (TGH) contribuyen a beneficios nutricionales en la salud, tales como el mejoramiento de la digestión de lactosa y el alivio de ciertos tipos de diarreas $(5,8,9)$. La MIH es objeto de numerosas investigaciones, con especial interés en la secuenciación del genoma de las bacterias que la conforman (10), es así que en la actualidad se llevan a cabo el Human Microbiome Project (HMP) en USA y el Metagenomics of the Human Intestine (metaHIT) en Europa y sus investigaciones han reportado que el organismo humano consiste en $10^{13}$ células eucariotas y $10^{14}$ microbianas, 
donde las más de 1000 especies bacterianas en el ambiente gastrointestinal humano $(A G H)$ inciden en la regulación del equilibrio homeostático con el hospedero o en el desenlace de una enfermedad (7). Estos avances describen aspectos importantes de la MIH tales como su capacidad de adherirse a las proteínas del hospedero (colágeno, fibrinógeno, fibronectina) y por lo tanto, la adherencia como un prerrequisito para una persistencia de las cepas bacterianas en el AGH (11). Asimismo, señalan beneficios de la interacción entre la microbiota y el organismo hospedero, atribuidos en gran parte a la $\mathrm{MIH}$, tales como la participación en la formación de la pared intestinal, la resistencia a la colonización y la producción de ácidos grasos de cadena corta. Estos metabolitos juegan un papel fisiológico importante, como el ácido acético en los músculos, corazón y cerebro, el ácido propiónico en la gluconeogénesis y el ácido butírico en la función de los enterocitos $(11,12)$. La MIH es capaz de mejorar las interacciones con el sistema inmune de las mucosas y la degradación de xenobióticos $(6,11,13)$. La inmensa diversidad de la $\mathrm{MIH}$, la variación interpersonal y fluctuaciones temporales en la composición, especialmente durante la enfermedad y su desarrollo temprano son retos que impactarán en el control de $\operatorname{EDAs}(5,7,11)$.

Los probióticos definidos por la FAO/WHO (2011), como microorganismos vivos que confieren beneficios a la salud del hospedero, incluyen Lactobacillus sp. y Bifidobacterium sp., microorganismos comúnmente utilizados como probióticos junto con ciertos tipos de levaduras y otras BAL $(12,14)$. Las características de un probiótico fueron definidas por Kamlesh et al (2011) (14). L. acidophilus se encuentra en el TGI y en ese nicho resiste la acción de ácidos orgánicos, sales biliares, la acidez y puede competir por nutrientes con microorganismos patógenos. Un estudio reporta el potencial probiótico de $L$. acidophilus en el control de Salmonella (15). Otro reporta su capacidad para estimular la producción de IgA en TGI, la producción de linfocitos e inhibición de la adhesión e invasión de patógenos (13). Actualmente se estudia el efecto antioxidante de L. acidophilus y en modelos in vivo se encontró una disminución en los niveles de glucosa en la sangre de pacientes con diabetes tipo 2 (16).

En este escenario, los probióticos se constituyen en una potencial herramienta para estimular la salud humana y animal (17-19). Por tanto, esta investigación tuvo como objetivo evaluar el efecto inhibitorio in vitro e in vivo de $L$. acidophilus1 aislado de TIH, sobre la cepa patógena de referencia $V$. cholerae 01 OGAWA en conejos lactantes.

\section{MATERIALES Y MÉTODOS}

\begin{abstract}
Aislamiento de BAL de tracto intestinal humano. Se aisló el microorganismo de muestras de materia fecal (MF) según recomendaciones descritas en literatura especializada $(18,19)$. Las BAL fueron aisladas de MF de cinco infantes (I1 =tres años de edad, I2=dos meses, I3=cuatro años, I4=un año e I5=trece años) las cuales fueron tomadas durante cinco días consecutivos $(a, b, c, d, e)$ para un total de 25 muestras. Se incluyeron niños con nulos antecedentes de diarreas y sin terapia con antibióticos.
\end{abstract}

Las colonias compatibles con BAL se repicaron en agar MRS azul de anilina hasta observar cultivos axénicos. La conservación se realizó en tioglicolato más glicerol a $-25^{\circ} \mathrm{C}$ (20).

Capacidad amilolítica de BAL. Los cultivos en agar MRS-almidón fueron expuestos a vapores de iodo bisublimado que ante el almidón viró su color a un complejo café-azulado diferenciando sus límites con halos de hidrólisis del almidón. Al cabo de 2 min de exposición se tomaron las mediciones (21). Los resultados del diámetro del halo de hidrólisis en $\mathrm{mm}$ se estudiaron mediante análisis de varianza y posterior prueba de Tukey. Se seleccionó la bacteria con mejor capacidad amilolítica y el mejor sustrato amiláceo que permitió el crecimiento óptimo de la BAL fue estandarizado en un trabajo previo (20).

Identificación de BAL con mejor capacidad amilolítica. Se realizó mediante claves taxonómicas descritas en Bergey's Manual of Determinative Bacteriology (22) y pruebas bioquímicas de degradación de carbohidratos y utilización de aminoácidos en galerías API CH50 (biomérieux, Marcy l'Etoile, France).

Evaluación de parámetros de fermentación. Para estimar la producción de biomasa se utilizó el método de recuento en placa en agar MRS. La determinación de proteínas se realizó por el método de Lowry. La determinación de azúcares y ácido láctico se realizó por cromatografía líquida de alta eficiencia (HPLC) (20).

Ensayo de antagonismo in vitro del probiótico sobre $\boldsymbol{V}$. cholerae 01 OGAWA. Se aplicó el método de difusión en pocillos descrito por Alvarado et al (23). A la BAL en el sustrato amiláceo elegido se le realizaron 3 diluciones $\left(10^{-1}, 10^{-2}, 10^{-3}\right)$ en SSF y en cada una de ellas se ajustó la densidad celular del inóculo en cámara de Neubauer. Posteriormente, se vertieron $40 \mu \mathrm{l}$ de cada suspensión celular en pozos de $7 \mathrm{~mm}$ de diámetro en agar MRS. Luego se cubrió con una capa de agar TCBS con $25 \mu$ de inóculo de 
V. cholerae. Lo anterior se incubó a $35^{\circ} \mathrm{C}$ por $48 \mathrm{~h}$, tiempo en el cual se midieron los halos de inhibición del probiótico sobre el patógeno (20). Se aplicó un diseño irrestrictamente al azar con arreglo bifactorial combinatorio y 10 replicas, donde el factor $\mathrm{A}$ correspondió a dos niveles de sustrato: $a_{1}=$ melaza con leche en polvo y $a_{2}=$ MRS; y el factor $B$ correspondió $a$ cuatro niveles de dilución del sustrato, a saber: $b_{1}=$ sustrato puro, $b_{2}=10^{-1}, b_{3}=10^{-2}$ y $b_{4}=10^{-3}$. La unidad experimental estuvo representada por una caja petri y un total de 80 unidades experimentales. Con el objeto de uniformizar las observaciones, previo análisis del Test de Bartley y Harley, estas se transformaron mediante raíz cuadrada de $X$, donde $X$ fue la observación. Los datos se sometieron a ANDEVA y prueba de Tukey para comparar las medias de los tratamientos en aquellas fuentes de variación que resultaron estadísticamente significativas, $\mathrm{p}<0.1$.

\section{Ensayo de protección del probiótico contra} $V$. cholerae 01 Ogawa en conejos lactantes. El ensayo in vivo se realizó tomando como modelo animal, conejos lactantes. Luego de administrar una dosis de $0.5 \times 10^{8} \mathrm{bact} / \mathrm{ml}$ más del $95 \%$ de los conejos desarrollaron enfermedad diarréica y la sobrevida promedio después de ser retados con el enteropatógeno fue de 13 días, tiempo de seguimiento para el ensayo de protección. Se analizaron cuatro grupos con 60 conejos lactantes cada uno. Tres grupos recibieron tratamiento para evaluar el efecto protector y en el cuarto se evaluó el efecto terapéutico del producto alimenticio. El grupo 1 recibió el fermento láctico como parte suplementaria de su dieta: únicamente leche materna; como primer control, el grupo 2 recibió el sustrato amiláceo elegido, sin fermentar; como segundo control, el grupo 3 no recibió ningún suplemento, solo fueron lactados por sus madres; y el grupo 4 recibió el fermento láctico luego de ser retado con el patógeno, para observar el efecto terapéutico del probiótico. Todos los animales fueron lactados por sus madres durante los 21 días del ensayo. Para el ensayo de protección se utilizó L. acidophilus1, cultivado en el sustrato amiláceo elegido hasta el tiempo de cosecha. El patógeno para el reto fue $V$. cholerae 01 OGAWA, luego de incubación en caldo TCBS a $37^{\circ} \mathrm{C}$ por $12 \mathrm{~h}$ (24).

Respecto a la alimentación con el probiótico, el grupo 1 de conejos se alimentó con éste desde el día del nacimiento hasta el día 21 , con un volumen de $50 \mu$ que contenía $1 \times 10^{5}$ bacterias durante 3 veces al día. El grupo 2 se alimentó con el sustrato amiláceo elegido en iguales dosis; el grupo 3 no recibió ningún suplemento alimenticio y el grupo 4 se alimentó con el producto probiótico a partir del mismo día que aparecieron los síntomas de diarrea, en iguales dosis que los anteriores. El reto de los animales se realizó con una dosis previamente estandarizada del patógeno $\left(0.5 \times 10^{8} \mathrm{bact} / \mathrm{ml}\right)$ siete días después de su nacimiento. Esta cantidad fue distribuida a su vez en 4 dosis de $250 \mu \mathrm{l}$ cada $6 \mathrm{~h}$ con cánula esofágica de $1.0 \mathrm{~mm}$ de diámetro útil.

El poder de colonización del lactobacilo y la inhibición de la colonización del patógeno se evalúo indirectamente, practicando recuentos de colonias de bacterias lácticas y $V$. cholerae de heces de conejos lactantes, tanto de retados como no retados. Las muestras se tomaron diariamente durante los 13 días del ensayo pos infección.

Los datos se analizaron con el programa STATA 10.0. El plan de análisis requirió de una base de datos con las medidas de peso diario de los conejos, sobrevida y cuantificación del número de UFC de $L$. acidophilus1 y $V$. cholerae 01 OGAWA, e incluyó el test de análisis de variantes de una vía, prueba de rangos múltiples DUNCAN y un análisis de estimación de sobrevida por Kaplan-Meier. Se utilizó el test de ANOVA, para evaluar la significancia de los resultados de protección en el modelo animal. Esta investigación fue avalada por el Comité de Ética en Investigación de la Universidad de Nariño.

\section{RESULTADOS}

Aislamiento de BAL. Se obtuvieron 75 aislados en agar MRS-azul de anilina compatibles con BAL. La pureza de los cultivos se verificó con la coloración de Gram encontrando bacilos Gram positivos y catalasa negativos (20).

Capacidad amilolítica. 8 de los 75 aislados fueron positivos en la prueba de hidrólisis del almidón. La BAL con mejor capacidad amilolítica fue seleccionada luego de analizar el diámetro de los halos (en $\mathrm{mm}$ ) de degradación de almidón mediante análisis de varianza y prueba de Tukey, $\mathrm{p}<0.5$. Así, de los 8 fue seleccionado el aislado del individuo (I) de dos meses de edad (2), de la primera y quinta muestra (a) y (e), purificado a partir de la dilución $10^{-5}(5)$, identificados como I2a5 e I2e5 (Figura 1).

Identificación del aislado. Los resultados de las pruebas microbiológicas, fisiológicas y bioquímicas realizadas, permitieron identificar el aislado como Lactobacillus acidophilus1 (Tabla 1).

Elección del sustrato. Se seleccionó el medio de melaza-leche para el cultivo de $L$. acidophilus1, teniendo en cuenta las condiciones de crecimiento recomendadas por Heczko et al (8). Las condiciones de fermentación fueron estandarizadas previamente (20). 


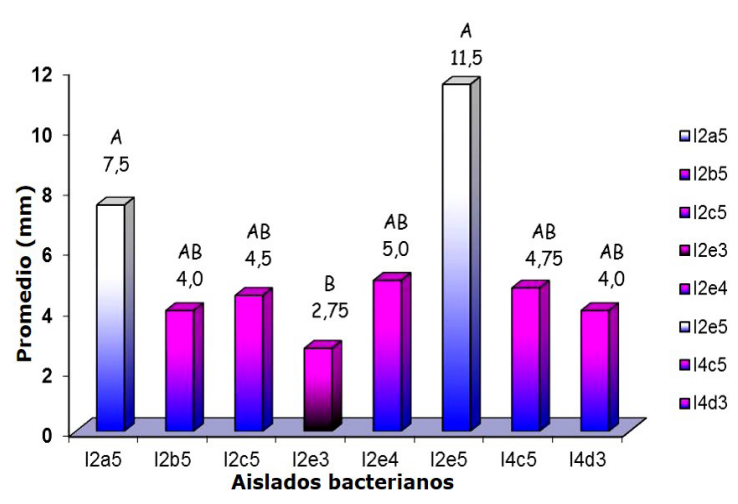

Figura 1. Promedios (en $\mathrm{mm}$ ) de los halos de hidrólisis del almidón para BAL y resultados de la prueba de Tukey. Las barras con los promedios ( $\mathrm{mm}$ ) y la misma letra $(A, A B$ y $B)$ no presentaron diferencias significativas entre ellas. Individuos de dos meses de edad I2a5, I2b5, I2c5, I2e5, I2e3 e I2e4, a partir de las cuales fueron aisladas las BAL. I4c5 e I4d3 BAL aisladas a partir de niños de un año de edad.

Tabla 1. Características microbiológicas, fisiológicas y bioquímicas de $L$. acidophilus 1 .

$\begin{array}{ll}\begin{array}{c}\text { Características } \\ \text { microscópicas }\end{array} & \begin{array}{l}\text { Bacilos Gram positivos, cortos, en empalizada, no } \\ \text { esporulados. }\end{array} \\ & \begin{array}{l}\text { Temperatura óptima de crecimiento } 30-36^{\circ} \mathrm{C}, \\ \text { tolerante de } 18-40^{\circ} \mathrm{C} .\end{array} \\ \text { Propiedades } & \\ & \begin{array}{l}\text { Crecimiento a } 45^{\circ} \mathrm{C} \text { negativo. Tolerante al rango de } \\ \text { pH } 3.8-6.5 .\end{array} \\ & \text { Homofermentativa. Altamente productora de ácido } \\ & \text { láctico. } \\ & \begin{array}{l}\text { Producción de ácido acético, succínico, fórmico, } \\ \text { propiónico y cítrico. }\end{array} \\ \text { Metabolismo } & \begin{array}{l}\text { Prueba de NaCl } 10 \% \text { negativa; glucosa, sacarosa, } \\ \text { trehalosa, lactosa, manosa, esculina, maltosa y } \\ \text { salicina positiva; gelatina, caseína, rafinosa, ramnosa, } \\ \text { xilosa y arabinosa negativas. }\end{array}\end{array}$

Evaluación de parámetros de fermentación de L. acidophilus1 en el medio melaza-leche. En este sustrato amiláceo se obtuvo alta producción de ácido láctico $(67.3 \mathrm{~g} / \mathrm{l})$ y un alto rendimiento de ácido láctico en relación con el consumo de azúcares (Figura 2). Al estimar la masa celular y la producción de proteína se determinó el tiempo de cosecha a las $14 \mathrm{~h}$, con $75 \times 10^{8}$ UFC de L. acidophilus $1 / \mathrm{ml}$ y una concentración proteica de $14.5 \mathrm{~g} / \mathrm{l}$.

Ensayo de inhibición antagónica in vitro. LOS resultados del análisis de varianza y la prueba de Tukey $(p<0.1)$ para los halos de inhibición, permitieron determinar que el fermento láctico inhibe el crecimiento in vitro del patógeno $V$. cholerae a una densidad celular de $35 \times 10^{6}$ bact/ $\mathrm{ml}$ presente en la dilución $10^{-1}$, respecto al sustrato puro (sin diluir) y a las diluciones $10^{-2}$ y $10^{-3}$.

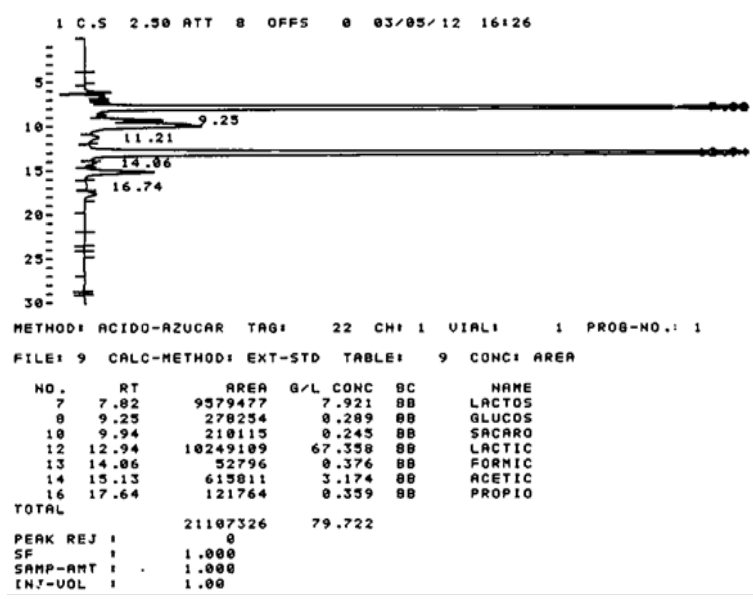

Figura 2. Cromatograma de producción de ácido láctico por HPLC. A las 24 horas de fermentación en el medio melaza-leche $L$. acidophilus 1 produjo $67.3 \mathrm{~g} / \mathrm{l}$ de ácido láctico. Fuente esta investigación.

\section{Protección intestinal contra $V$. cholerae 01 OGAWA por cultivos probióticos en modelo} animal. El ensayo de protección intestinal contra $V$. cholerae 01 OGAWA a través de la administración oral de un fermento láctico que contuvo $L$. acidophilus1 revistió la mayor relevancia del presente estudio y condujo a probar la hipótesis de protección intestinal in vivo (Figura 3).

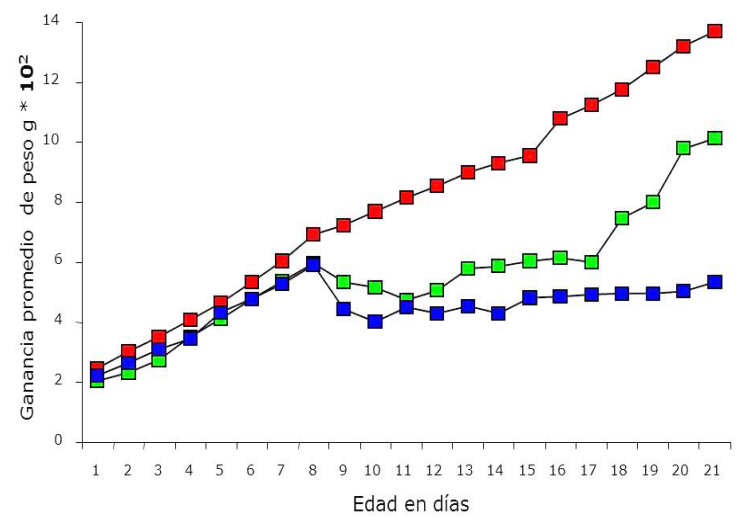

Figura 3. Ganancia de peso promedio en conejos retados con V. cholerae según tipo de alimento. En los tres grupos de conejos retados con el patógeno se observan diferencias en el peso promedio. El grupo con mayor ganancia en peso es el tratado con probióticos (cuadros rojos) 130.7 g, luego el grupo tratado con sustrato amiláceo sin BAL (cuadros verdes) $100.2 \mathrm{~g}$ y por último el grupo control, alimentado solamente con leche materna (cuadros azules) con $50.3 \mathrm{~g}$, al final del ensayo, $p=0.00$. 
Estos resultados significarían que la administración oral de probióticos está relacionada con una mejor nutrición de los animales, evidenciado por la ganancia en peso del grupo tratado con el fermento láctico.

Por otra parte, hubo una pérdida de peso promedio, a los 7 días de nacidos, en dos grupos de conejos inoculados con $V$. cholerae 01 OGAWA, los conejos infectados con síntomas de diarrea perdieron peso hasta un día posterior al tratamiento con probióticos (Figura 3). Así mismo, hubo una ganancia gradual de peso promedio en el grupo tratado con probióticos, respecto al grupo de conejos lactados (Figura 3, 4).

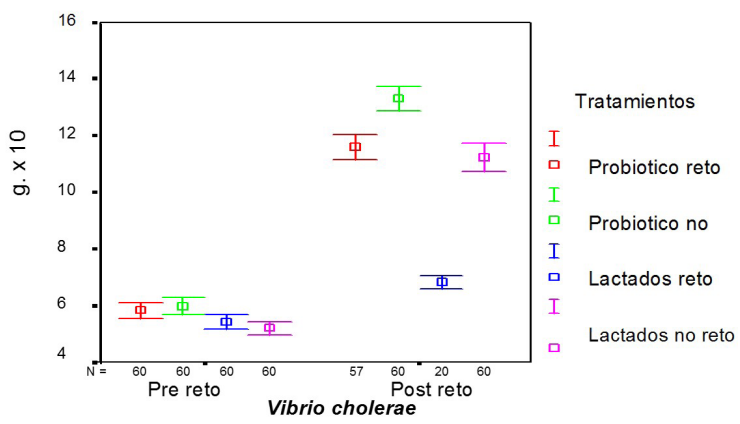

Figura 4. Desviaciones estándar (DS) y diferencias promedio de pesos de conejos pre y post reto con $V$. cholerae según tratamientos. La DS del promedio de peso de conejos alimentados con probióticos (rojo o verde) y las DS de los lactados (azul o fucsia). g.=gramos. Pre reto: Día 7 del ensayo. Pos reto: Día 21 del ensayo. $\mathrm{N}=$ número de individuos vivos.

Del análisis pre y post reto según tratamientos, se puede decir que hubo una menor ganancia promedio de peso antes del reto $p<0.05$ en los grupos de animales que no recibieron probióticos (DS azul o fucsia). Las diferencias de pesos promedio a los 21 días del ensayo fueron estadísticamente significativas, $p<0.05$. Después del reto el beneficio del probiótico se observó en los animales protegidos y retados (DS en rojo), pues tuvieron ganancia de peso similar al grupo control (DS en fucsia), de ésta manera se logró evidenciar que la ausencia del reto y la protección con probióticos favorecen el crecimiento y desarrollo de los animales significativamente.

El efecto terapéutico del probiótico se manifestó en la recuperación y la ganancia de peso observada luego del proceso infeccioso, en comparación al grupo lactado (control). Los promedios de pesos al final del ensayo fueron $70.8 \mathrm{~g}$ y $50.3 \mathrm{~g}$ para los grupos tratados y no tratados con probióticos respectivamente.
Análisis de sobrevida. La protección intestinal del probiótico contra $V$. cholerae fue demostrada en el análisis de sobrevida (Figura 5). Se puede observar que los conejos enfrentados con el patógeno y sin recibir probiótico (lactados) tuvieron una probabilidad de sobrevida menor respecto al grupo de animales retados con el patógeno y simultáneamente alimentados con probióticos, cuya probabilidad de sobrevida fue mayor.

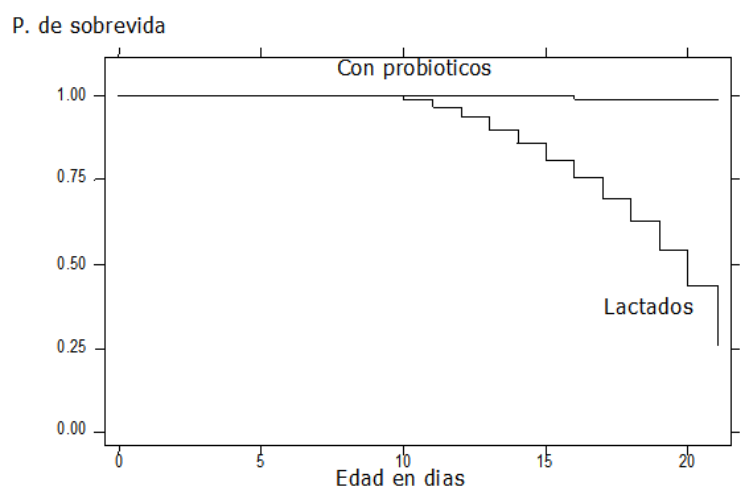

Figura 5. Estimación de sobrevida por Kaplan-Meier en conejos retados con $V$. cholerae según tratamiento. Se observa a la derecha de la figura una linea escalonada que describe la mortalidad de los animales retados y no alimentados con probióticos, estos tienen un probabilidad de sobrevida de 0.25 a los 21 dias, en comparación a 0.95 de probabilidad de los conejos retados y alimentados con probióticos.

Evaluación del poder de colonización de $L$. acidophilus1 y $V$. cholerae 01 OGAWA en heces. En la figura 6 se observa al día ocho o un día post-reto la aparición de un pico de infección por V. cholerae 01 OGAWA (cuadro verde, Figura 6), coincidiendo con los síntomas de diarrea y pérdida de peso observados entre el octavo y décimo día del ensayo (cuadros verdes y azules, Figura 3).

La colonización por $V$. cholerae 01 OGAWA solo se manifestó en los recuentos de colonias promedios de las muestras de heces de los conejos retados dos días post-reto (cuadro verde), sugiriendo que existe una protección contra la colonización de $V$. cholerae 01 OGAWA en los siguientes días del ensayo en el grupo tratado con probiótico, lo que no sucedió con el grupo control (lactados), en los cuales los recuentos de UFC $V$. cholerae 01 OGAWA $/ g$ de heces en los siguientes días post inóculo tuvieron su expresión máxima en el día 9 con $1.2 \times 10^{7} \mathrm{UFC} / \mathrm{g}$ de heces y cayeron gradualmente hasta el día 11. 


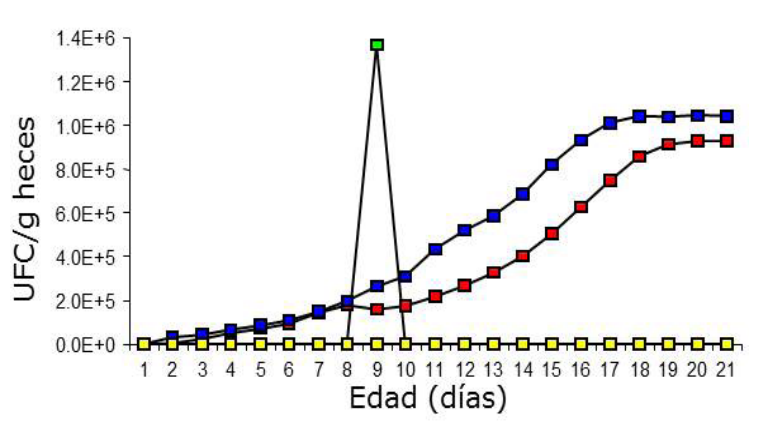

Figura 6. Recuento de $L$. acidophilus y $V$. cholerae 01 OGAWA en coprocultivos de conejos alimentados con probióticos. Los cuadros rojos son UFC/g de heces de $L$. acidophilus1 del grupo alimentado con probiótico a los 7 días de retado con $V$. cholerae. Los cuadros azules son UFC/g de heces de $L$. acidophilus 1 del grupo alimentado con probiótico pero no retado con $V$. cholerae; el cuadro verde son $\mathrm{UFC} / \mathrm{g}$ de heces de $V$. cholerae del grupo control a los 7 días de retado con $V$. cholerae y los cuadros amarillos son UFC/g de heces de $V$. cholerae del segundo grupo control lactado pero no retado con $V$. cholerae.

\section{DISCUSIÓN}

Los probióticos se utilizan para tratar enfermedades gastrointestinales, incluyendo enfermedades inflamatorias del intestino, síndrome del intestino irritable y EDAs (25). Los mecanismos por los cuales los probióticos protegen contra las enfermedades intestinales incluyen la optimización del equilibrio microbiano, exclusión competitiva de patógenos, promoción de la secreción de moco, producción de bacteriocinas, mejora de la integridad de la barrera y maduración de la inmunidad intestinal $(6,25)$.

En humanos, la administración del probiótico $L$. acidophilus, reduce significativamente la incidencia de la enterocolitis en recién nacidos (26). Un mecanismo importante incluye la función de barrera, garantizada por el mantenimiento y estabilidad de las uniones celulares. Esta BAL tiene efecto anti-inflamatorio y citoprotector, más específicamente en EDA donde se puede constituir en una nueva herramienta de prevención en la población vulnerable, como recién nacidos y prematuros $(19,26)$.

Las BAL aisladas con capacidad amilolítica se obtuvieron en mayor proporción de niños recién nacidos porque en niños de más de un año no fue posible seleccionar BAL con las características requeridas. Este hallazgo según Gibson et al
(5) se debe posiblemente a que con la edad el cambio en la dieta, en el metabolismo y la exposición a infecciones concomitante con el uso de antibióticos, induce un aumento en la variabilidad del microbioma intestinal nativo $(7,12,26)$.

L. acidophilus1 se puede considerar un microorganismo probiótico dado que en el presente estudio se evidenció que su consumo puede proporcionar beneficios en la salud de los animales, además es resistente a la acidez del TGI y cuando se ingiere es capaz de sobrevivir a su paso por el TGI dado que fue recuperado a partir de heces frescas de conejos lactantes tratados con el alimento probiótico. Así, todas estas características se ajustan a las descritas por Kamlesh et al (14) y Khani et al (19) para un microorganismo ser considerado como probiótico.

Los ensayos de fermentación permitieron conocer la respuesta metabólica de $L$. acidophilus1 a diferentes fuentes de carbono y nitrógeno (20). Los azúcares consumidos del medio de cultivo favorecen la producción de ácido láctico en altas concentraciones, este comportamiento permitió determinar el carácter homofermentativo de la bacteria L. acidophilus1 y su potencial industrial para la producción de este metabolito. Se encontró que L. acidophilus 1 inhibe el crecimiento in vitro del patógeno $V$. cholerae a una densidad celular de $35 \times 10^{6}$ bact $/ \mathrm{ml}$ presente en la dilución $10^{-1}$ respecto al sustrato puro y a las diluciones $10^{-2}$ y $10^{-3}$, resultados concordantes con un estudio previo (16).

La sobrevida de los conejos infectados con $V$. cholerae del grupo tratado con probiótico fue mayor respecto a los grupos control, pues así lo confirma el análisis de sobrevida $p<0.05$. Se puede concluir entonces que el probiótico tiene un efecto protector en conejos contra el patógeno $V$. cholerae 01 OGAWA. El beneficio del probiótico se observa en forma contundente en los animales protegidos y retados, pues tuvieron ganancia de peso similar al grupo control (lactado), lo que sugiere que la ausencia del reto y la protección con probióticos favorecen el crecimiento y desarrollo de los animales, resultados que concuerdan con los hallazgos de Ritchie et al (27). El efecto protector o profiláctico del probiótico es mucho más evidente que el efecto terapéutico pues luego de la estimación de sobrevida por Kaplan-Meier, sólo el $10 \%$ de los conejos murieron, en comparación del $60 \%$ observado cuando se hizo uso del probiótico pos-reto. La medida terapéutica tomada en el estado álgido de la infección diarreica, se comportó de manera positiva, manifestándose 
en la inhibición de la colonización de $V$. cholerae, similar al hallazgo de Lee et al (28) evidenciado en la desaparición de la diarrea, resolución de la infección, ganancia promedio de peso de los animales, más no en la restauración del equilibrio de la microbiota láctica endógena, en contraste con la microbiota encontrada por Combes et al (34) y Chamorro et al (29) en conejos recién nacidos luego de la administración de formulas dietarias.

Nuestros hallazgos sugieren en un futuro el uso de $L$. acidophilus1 para restablecer o mantener el equilibrio de TGI luego del contacto con $V$. cholera y controlar la infección, en contraste a los recientes reportes sobre el uso de BAL como $L$. lactis para la elaboración de vacunas de administración oral, que potencia la respuesta inmune de la mucosa e inmunidad sistémica específica tipo IgA contra el patógeno $V$. cholerae $01(6,30,31)$ y la comprensión de cómo el sistema inmune adaptativo hace frente al notable número y diversidad de microbios que colonizan el TGI, este probiótico es muy prometedor para establecer nuevos enfoques de modulación de redes inmunes para tratar y prevenir la enfermedad (6).

Los resultados obtenidos en ratones permiten recomendar la administración oral de probióticos en humanos en riesgo de infección o incluso en situaciones de epidemias, debido al efecto altamente protector observado $(30,32)$.

En el futuro, si se tiene en cuenta que la interacción de las toxinas bacterianas con receptores de la superficie de las células hospederas (31) -tales como el receptor de Lipopolisacárido LPS- es un paso indispensable en la patogénesis del cólera, el bloqueo de tales interacciones es una potencial y atractiva estrategia terapéutica que conlleva al diseño y caracterización de la expresión de probióticos recombinantes, simulando la unión entre el receptor GM1 (galactomanósido 1) y Ctx (toxina cólera) e infectando ratones para comprobar los cambios con $V$. cholerae virulento. Sin embargo, es de tener en cuenta en el diseño y aplicación de vacunas o métodos profilácticos, que para $V$. cholerae se han documentado elementos genéticos móviles, integrones, fagos, islas de patogenicidad y otros elementos genéticos del "mobiloma" $(10,33)$ como resultado de los eventos de evolución genómica y procesos de transferencia lateral, que han conllevado a la emergente aparición de variantes de éste patógeno con capacidad de adaptación y poder patogénico incrementados, razón por la cual las investigaciones destinadas al diseño y uso de microorganismos probióticos u otras herramientas profilácticas o terapéuticas deberán tener en cuenta estos mecanismos. Los microorganismos probióticos son una herramienta promisoria para el equilibrio de la MIH, permite el subyacente control de $V$. cholerae, pues su capacidad de producir enzimas y activación de complejas vías metabólicas puede ayudar a generar ambientes hostiles para el patógeno.

En conclusión este trabajo encontró que existe una protección de la colonización de $V$. cholerae 01 OGAWA en el grupo de conejos lactantes tratados con $L$. acidophilus. Se pudo comprobar la hipótesis de estudio pues la sobrevida del grupo de conejos tratado con probióticos fue mayor a la del grupo lactado por sus madres y alimentado con el sustrato puro; entonces $L$. acidophilus tiene un efecto protector en conejos contra la cepa patógena de $V$. cholerae 01 OGAWA.

Una perspectiva de interés es comprender cómo la MIH afecta a la salud y la enfermedad y la biología de sus relaciones con L. acidophilus, de tal manera que propicie un cambio en la concepción de patógenos individuales como únicos agentes causales, hacia un enfoque ecológico teniendo en cuenta la comunidad y las condiciones del micro-nicho en su conjunto $(6,7,10)$.

\section{Agradecimientos}

A la Vicerrectoría de Investigaciones-VIPRI, de la Universidad de Nariño por la financiar el trabajo. Al Departamento de Biología. Al Grupo de Investigación Salud Pública de la Universidad de Nariño. A las Biólogas con énfasis en Microbiología. Nubia Yandar y Sofía Guzmán de la Universidad de Nariño. Al Profesor Luis E Bravo de la Universidad del Valle. 


\section{REFERENCIAS}

1. World Health Organization WHO. Number of reported cholera cases. Global Health Observatory (GHO); 2013.

2. INS. Boletín Epidemiológico No 35. Bogotá, Colombia: Instituto Nacional de Salud INS; 2013. URL Disponible en: http://www.ins. gov.co/boletin-epidemiologico/Boletn $\% 20$ Epidemiolgico/2013\%20Boletin $\% 20$ epidemiologico\%20Semana\%2035.pdf

3. Nomoto K. Prevention of Infections by Probiotics. Review. J Biosci Bioeng 2005; 100(6):583-592.

4. Binns C, Lee KM. The use of probiotics to prevent diarrhea in young children attending child care centers: A review. J Exp Clin Med 2010; 2(6):269-273.

5. Gibson GR, Probert HM, Loo JV, Rastall RA, Roberfroid MB. Dietary modulation of the human colonic microbiota: updating the concept of prebiotics. Nutr Res Rev 2004; $17(2): 259-275$.

6. Maynard CL, Elson CO, Hatton RD, Weaver CT. Reciprocal interactions of the intestinal microbiota and immune system. Nature 2012; 489(7415):231-241.

7. Lozupone C, Stombaugh J, Gordon J, Jansson J, Knight R. Diversity, stability and resilience of the human gut microbiota. Nature 2012; 489(7415):220-230.

8. Heczko PB, Strus M, Kochan P. Critical evaluation of probiotic activity of lactic acid bacteria and their effects. J Physiol Pharmacol 2006; 57(Suppl 9):5-12.

9. Ljungh A, Wadström T. Lactic acid bacteria as probiotics. Curr Issues Intest Microbiol 2006; 7(2):73-89.

10. Weinstock GM. Genomic approaches to studying the human microbiota. Nature 2012; 489(7415):250-256.

11. Aureli P, Capurso L, Castellazzi AM, Clerici M, Giovannini M, Morelli L, et al. Probiotics and health: An evidence-based review. Pharmacol Res 2011; 63(5):366-376.
12. Tremaroli V, Bäckhed F. Functional interactions between the gut microbiota and host metabolism. Nature 2012; 489(7415):242-249.

13. Galdeano CM, de Leblanc AM, Carmuega $E$, Weill R, Perdigón G. Mechanisms involved in the immunostimulation by probiotic fermented milk. J Dairy Res 2009; 76(4):446-454.

14. Kamlesh S, Basavaraj K, Ajay K, Vidhi T. Probiotics: A review. Asian Pac J Trop Biomed 2011; S287-S290.

15. Castillo NA, Moreno A, Maldonado GC, Perdigón G. Probiotics: An alternative strategy for combating salmonellosis Immune mechanisms involved. Food Res Int 2012; 45(2):831-841.

16. Chandrakant A, Marcia P, Duane G, Kalidas S. In vitro bioassay based screening of antihyperglycemia and antihypertensive activities of Lactobacillus acidophilus1 fermented pear juice. Innov Food Sci Emerg Technol 2012; 13(4):221-230.

17. Quigley EM. Gut microbiota and the role of probiotics in therapy. Curr Opin Pharmacol $2011 ; 11(6): 593-603$.

18. Guarner F, Khan AG, Garisch J, Eliakim R, Gangl A, Thomson A, et al. World gastroenterology organization global guidelines: probiotic and prebiotics. J Clin Gastroenterol 2012; 46(6):468-481.

19. Khani S, Hosseini HM, Taheri M, Nourani MR, Fooladi A. Probiotics as an alternative strategy for prevention and treatment of human diseases: A review. Inflamma Allergy Drug Targets 2012; 11(2):79-89.

20. Guerrero M, Guzmán S, Yandar M, Pazos A. Efecto inhibitorio de Lactobacillus acidophilus sobre el enteropatógeno $V$. cholerae 01 Ogawa in vitro. Universidad y Salud 2002; $1(3): 8-14$.

21. De Roissart IH, Editors. Bacteries Lactiques. 4th Ed. Montpellier: IRD; 1995.

22. Sneath P, Holt J.G. Bergey's Manual of Determinative Bacteriology. Vol III. 9th Ed. Estados Unidos: Williams and Wilkins Co; 1994. 
23. Alvarado CC, Díaz CG. Efecto antagónico de Lactobacillus plantarum aislado de pastizal de finca lechera. RESPYN [en linea]. 2009; 10(1). URL Disponible en: http://www. respyn.uanl. $\mathrm{mx} / \mathrm{x} / 1 /$ articulos/articulo_ lactobacillus_plantarum.htm.

24. CDC's Global Disease Detection (GDD) Manual: Rapid Diagnostic Test for Cholera. 2011.

25. Gareau MG, Sherman PM, Walker WA. Probiotics and the gut microbiota in intestinal health and disease. Nat Rev Gastroenterol Hepatol 2010; 7(9):503-514.

26. Sheng $S$, Yueyue $Y$, Guo $Y$, He $S$, Haikaeli $M$, Hoenig J, et al. Synergistic Protection of Combined Probiotic Conditioned Media against Neonatal Necrotizing EnterocolitisLike Intestinal Injury. PLoS One 2013; 8(5):6-19.

27. Ritchie JM, Rui H, Bronson RT, Waldor MK. Back to the future: studying cholera pathogenesis using infant rabbits. MBio 2010; 18(1):1-10.

28. Lee DJ, Drongowski RA, Coran AG, Harmon $\mathrm{CM}$. Evaluation of probiotic treatment in a neonatal animal model. Pediatr Surg Int $2010 ; 16(4): 237-242$.
29. Chamorro S, de Blas C, Grant G, Badiola I, Menoyo D, Carabaño R. Effect of dietary supplementation with glutamine and acombination of glutamine-arginine on intestinal health in twenty-five-day-old weaned rabbits. J Anim Sci 2010; (1):170-180.

30. Zamri HF, Shamsudin MS, Rahim RA, Neela V. Oral vaccination with Lactococcus lactis expressing the Vibrio cholerae Wzm protein to enhance mucosal and systemic immunity. Vaccine 2012; 30(21):3231-3238.

31. Linares DM, Geertsma ER, Poolman B. Evolved Lactococcus lactis strains for enhanced expression of recombinant membrane proteins. J Mol Biol 2010; 401(1):45-55.

32. Focareta A, Patón JC, Morona R, Cook J, Patona AW. Recombinant Probiotic for Treatment and Prevention of Cholera. Gastroenterol 2006; 130(6):1688-1695.

33. Safa A, Nair GB, Kong RY. Evolution of new variants of Vibrio cholerae 01 . Trends Microbiol 2010; 18(1):46-54.

34. Combes S, Michelland RJ, Monteils V, Cauquil L, Soulié V, Tran NU, et al. Postnatal development of the rabbit caecal microbiota composition and activity. FEMS Microbiol Ecol 2011; 77(3):680-689. 